\title{
The impact of social motivation on cooperative learning and assessment preferences
}

\author{
Christopher Selvarajah \\ Professor, Faculty of Business and Enterprise, Swinburne University, Australia \\ John Chelliah \\ School of Management, University of Technology Sydney, Australia \\ Denny Meyer \\ Faculty of Life and Social Sciences, Swinburne University, Australia \\ Edwina Pio \\ Associate Professor, AUT University, New Zealand \\ Pacapol Anurit \\ Assistant Professor, School of Management, Shinawatra University, Thailand
}




\title{
The impact of social motivation on cooperative learning and assessment preferences
}

\begin{abstract}
This study explores the assessment preferences of 453 postgraduate business students in New Zealand, Australia, and Thailand using a survey linking motivational and educational preferences. This comparative study of students from these three countries shows that students who are socially motivated prefer 'Cooperative Learning'. The study specifically shows that students from Thailand are more socially motivated than students from Australia and New Zealand (ANZAC) while International ANZAC students have the greatest desire for Cooperative Learning. This study compares the needs of Western students (Australian and New Zealand), Asian (Thai) and International students in a Western setting (Chinese and Indian foreign students), finding that group assessment poses quite significant challenges for universities, especially in the case of local ANZAC students.
\end{abstract}

Keywords - Assessment Preferences, Social Motivation, Cooperative Learning, International students, Australia, New Zealand, Thailand. 
"Put random collections of people into groups - for instance on a management training course and they will, if they wish to be a group ... start to find a name, or a private territorial sign, or a ritual, which will give them an independent identity. If they do not do this, it often means that membership of such a group is not important to them, that they are happy to remain a random collection of individuals”. (Handy 1985, 155)

\section{INTRODUCTION}

In the tertiary education context, group working methods and more specifically group work that is assessed, have, over the past fifteen years or so, become integral components of both undergraduate and postgraduate programmes. These days it is unusual for postgraduate and undergraduate students not to have been involved in group work situations as part of their education.

The aim of this article is to examine assessment preferences of postgraduate business students in New Zealand, Australia and Thailand. Following a brief introduction covering the background of group work in education and a review of the literature, the context of the study and the research hypotheses will be detailed. The results are then presented containing a detailed statistical analysis with discussion on the findings which are unique because of the international composition of the participants surveyed.

\section{BACKGROUND TO THE STUDY}

For many universities in Australia and New Zealand, international student recruitment is paramount. Universities in both these countries have looked to fee-paying international students both as a means of generating income and as a means of adding diversity to the student body (Ross, Heaney and Cooper, 2007). These universities have internationalization as a key strategic initiative with emphasis placed on the development of learning and teaching approaches that ensure international students are fully involved in classroom, group work and assessment activities for the benefit of all students (AUT 2005: 10).

A New Zealand Ministry of Education report on 'The impact of international students on domestic students and host institutions’ (Ward 2001: 1) reports: “On the whole, research suggests that international students expect and desire contact with their 
domestic peers, and positive social, psychological, and academic benefits arise from this contact; however, the amount of interaction between international and domestic students is low". The report suggests the need for strategic interventions like peer pairing and Cooperative Learning to improve interaction between international and domestic students. This suggestion initiated this study.

\section{REVIEW OF LITERATURE}

The term "Cooperative Learning", is often used interchangeably with collaborative learning, group learning, peer learning, learning community, and constructive learning, has become a common practice in tertiary institutions in New Zealand and elsewhere (Ward \& Masgoret 2004, Sherman 2000; Brody 1995).

In explaining “Cooperative Learning”, Johnson (1979) described three types of behaviour settings, which are called "goal structures." The three goal structures are Cooperative, Competitive, and Individualistic. As Johnson explains, these goal structures are primarily based on the presence or absence of interdependence among classroom members. Sherman (2000) states that cooperative goal structures operate when two or more individuals are in a situation where the task-related efforts of individuals help others to be rewarded. Other attributes considered important in defining cooperative goal structure are: face-to-face interactions, heterogeneous groupings, individual accountability, group processing, and positive interdependence.

In practice, “Cooperative Learning” involves dividing students into small groups to learn content knowledge, to explore or discuss an assigned topic, or to complete cases, projects and group assignments, to answer a few challenging questions, or to engage in an exchange of ideas, and share some insights with group members (Li \& Campbell 2008; Porter 2006). The common techniques include 'Socratic questioning, problem-based learning, case studies, role playing, critical thinking, and behavioral analysis' (Porter 2006: 1). Group work forms a large, growing role in business education. Rapid growth in student numbers has created pressure for more efficient methods of teaching. Efficiency in teaching can generally be accommodated through increasing the size of lectures and seminar groups. But the pressure on other components of teaching especially marking 
papers becomes more severe. Thus, universities turn to things like group projects to reduce marking load of academics (Nordberg, 2008).

Therefore, in a world with increasing demographic changes, globalization, currency fluctuations, ecological and ethnic consciousness, it is imperative that educational institutions prepare their students for negotiating the reality of a multicultural environment. For business courses, such a stance assumes increasing importance in consideration of the reality of global conglomerates, multi-national corporations, expatriate employees, and migrant workers.

A major driver of learning is assessment. Within assessment is embedded a complexity that includes power as a basis for gaining qualifications, as well as learning opportunities which challenge both student and teacher while preserving the legitimacy of the institution (Pio 2004). In contrast, assessments in Asian education systems are based on rote memorization (Cavallo and Schaffer 1994). Ryan and Louie (2007) are however, of the view that both domestic and international students lead multi-layered lives in which the East West divide is only one characteristic amongst many. Therefore, understanding the cultural and social needs of the students is but the beginning. In a social construction approach to knowledge, students can be positioned, nurtured and facilitated to be critical thinkers and social agents of change who feel empowered when they can access new knowledge in addition to seeing themselves in history with a relevant degree and better employment prospects (Lee 2005; Pearson and Chatterjee 2004; Sen Gupta 2003; Wong, 2001). In a constructivist approach students are primarily motivated by their interest and curiosity in the subject whereas in the empiricist approach students are mainly motivated by performance in examinations (Tsai, 1998). Tsai through his research demonstrated that students holding constructivist oriented epistemological beliefs tend to use more meaningful-learning strategies whereas students with empiricist oriented epistemological beliefs tended to use rote learning when acquiring knowledge.

Assessment of student learning can be predicated on various conceptualizations of mastery and can include rational comprehension of content, collaborative ability through peer interaction and knowledge application through small group projects. Cooperative Learning and performance based assessment (McBurnie 2000; Morey 2000; Lewis 1997). Moreover alternative assessment forms in a multicultural context need to move away 
from assessments which have primarily been used to demonstrate expertise by white middle class male students, dominant culture epistemologies, standardized tests and the Anglo-European concept of competition and individual student achievement (Lynch 1997; Bishop and Glynn 1999; Clark 2002). A multicultural context is necessary because it prepares all students for a world in which cultural border crossing is the norm rather than the exception (Giroux, 1992). In recent times, discussion and debate surrounding multiculturalism curriculum transformation focuses not on whether to undertake it but rather on how to engage in it effectively (Nieto, 2000).

Leask (2001: 110) suggests that the assessment profile facilitate independent and collaborative learning through a range of group and individual projects so that "students are required to work with others, consider the perspectives of others, and compare them with their own perspectives...in embracing the content and pedagogies of others". Mackinnon and Manathunga (2003: 132) state: "If our assessment continues to be based upon a Western template of knowledge that only values Western ways of knowing and learning, all our lip service to developing interculturally competent students is meaningless. It also institutionalises discrimination against students from non-dominant backgrounds and privileges students from dominant groups.”

Interestingly assessment is often considered the poor relation in discourses on learning and teaching (Allen, 2004). To counteract this view, a series of studies using an instrument developed by Selvarajah (2006) seek to explore assessment preferences among students. Furthermore, "higher education is now international in a way it has not been since the heyday of Europe's great medieval universities...with two million university students studying outside their home in 2003, and an annual fee income estimated at US\$39 billion” (The Economist, 2005: 63). Hence the Selvarajah (2006) instrument incorporates ethnicity of students in its design, allowing the comparison of Thai students with local and international ANZAC students in this study. It is worthy of note that student assessment preferences do not necessarily mean effective and reliable assessment outcomes.

The New Zealand and Australian tertiary education sector has a rich diversity of ethnicities from migrants and international full fee-paying students, while the Thai tertiary education system appears to be more homogeneous. A New Zealand Ministry of 
Education report on 'The impact of international students on domestic students and host institutions” (Ward 2001: 1) reports: “On the whole, research suggests that international students expect and desire contact with their domestic peers, and positive social, psychological, and academic benefits arise from this contact; however, the amount of interaction between international and domestic students is low”. The report suggests the need for strategic interventions like peer pairing and Cooperative Learning to encourage the academic interaction between international students and their domestic peers. Appropriately most New Zealand and Australian universities have internationalization as a key strategic initiative, emphasizing the development of learning and teaching approaches to ensure that international students are fully involved in classroom, group work and assessment activities for the benefit of all students (AUT 2005: 10).

For immigrants and international students Cooperative Learning is believed to be particularly appealing because it helps them learn about local customs and procedures and may help them practise a new language (Long and Porter, 1985; Pica, Young, and Doughty, 1987). Interaction in the Cooperative Learning groups is said to contribute to academic achievement (Bejarano 1987; Ghaith and Yaghi 1998; Kagan 1989, Ghaith 2002; 2003) and the learning experience goes beyond mere receptive understanding to multiple sources of information access and tasks (Olsen and Kagan 1989). More importantly, this attraction seems to cross boundaries of race, gender, disability and ethnicity (Kohn, 1987). It is likely that people who are motivated to study by the promise of Cooperative Learning will be more in favour of group assessment, particularly if they enjoy Cooperative Learning (Johnson and Johnson, 1975; 1984). This heightened Social Motivation and desire for Cooperative Learning and group assessment amongst international students is tested in this study in the first hypothesis, involving a comparison of international students in New Zealand and Australia with local students in New Zealand, Australia and Thailand.

Hypothesis 1: The importance of Social Motivation and preferences for Cooperative Learning and group assessment will be stronger amongst international ANZAC students than amongst local ANZAC students or Thai students. 
Cooperative Learning teaches skills that are needed in the workforce skills; such as teamwork, communication, leadership, and management. Johnson \& Johnson (1990) and Slavin (1995b) found students engaged in Cooperative Learning were more likely to use cooperative behaviours they were taught when they worked with new classmates. Candy (1991) affirms that professional learning is essentially experiential and that skills are acquired and refined through social interactions, dialogue, and negotiation with others. This poses a particular challenge for web-based learning prompting McLoughlin and Luca (2002) to stress the importance of online group discussion. The social dimension is an aspect that is missing in many web-based learning programmes. Research (Gerlach 1994) shows that the social context is what makes the group work. This means that the ways in which men and women and the members of various minorities and ethnic groups are socialized into holding different but valid ideas is what makes the group work.

In this study, the dimension of Social Motivation as a construct in support of Cooperative Learning is introduced. The factors generated to measure Social Motivation are intrinsic values built on individual needs for working with other cultures, building new friendships, improving communication and work skills, and to improving and increasing social networks. Many students enjoy Cooperative Learning because it helps them make new friends and useful business contacts, bringing them into contact with people from other cultures (Slavin 1980). The Social Motivation of students is therefore expected to influence expectations in terms of Cooperative Learning and assessment preferences and this is tested in the first hypothesis detailed below.

Hypothesis 2: Students who have stronger Social Motivation are more likely to favour Cooperative Learning and group assignments rather than individual assignments.

Studies (Cohen 1994; Dornyei, 1994, 1997) also show that Cooperative Learning enhances motivation and psychological adjustment of learners. Another advantage of Cooperative Learning is the reduced marking load for teaching staff when there is group 
assessment. However, this is off-set by the increase in time spent in preparation and often facilitation of the group process.

Group assessment is not always popular amongst students and Garfield and Gal (1999) have included this topic amongst the current assessment challenges in education. A common complaint amongst students is that group assessment is unfair. It is often felt that some group members do not pull their weight while others are forced to work much harder in order to make up for the deficiencies in the performance of other team members. Nordberg's (2008) research showed that some students with English as their mother tongue complained about being turned into mere scribes by their groups. Others complained of being expected to do far more than their share of group tasks. "Even groups with a dominant national background had difficulties, as those with better English-language skills felt peer pressure to do the bulk of the preparation of written work..." (Nordberg 2008:484). Grading systems have been developed in order to address these perceived weaknesses in group assessment (Sherman, 2000). For example in some classes students are asked to rate the performance of their fellow group members and these ratings are taken into consideration in the final grades. In a US-based study, Barfield (2003) found that student views of the fairness of self and peer assessment depended on the age and status of the students, including how familiar they were with group work and group assessment:

- the less experience of group grading students had, the more likely they were to agree that all deserve the same mark;

- students who worked only part time while studying were more likely to think that a group grade was a fair assessment of their contributions than students who worked full time;

- older students were more likely to be dissatisfied with a group grade experience than middle and younger aged students;

However, some educationists argue that it is the hard working high performance contributors in teams who benefit most from group assessment (Clark 2002; Leask 2001). In having to explain concepts to weaker team mates they obtain additional understanding, and, in having to conduct more of the work they are better prepared for any ensuing examinations or work tasks. 
Though Thailand is a collectivist country where social norms are important in comparison to the west (Hofstede 2003), like most Asian societies the education systems are based on rote memorization (Cavallo and Schaffer 1994). Due to the more monocultural nature of tertiary education in Thailand it is expected that Social Motivations, Cooperative Learning and group assessment will be considered to have less importance in Thailand and that the relationships between these variables will be weaker.

In the third hypothesis the strengths of the relationships between Social Motivation, Cooperative Learning and Preference for Group Assessment are compared for these same student groups.

Hypothesis 3: The above relationship (Students who have stronger Social Motivation are more likely to favour Cooperative Learning and group assignments rather than individual assignments) will be stronger for international ANZAC students than for local ANZAC students or Thai students.

The literature covered Selvarajah's ${ }^{1}$ (2006) cross-cultural study of educational methodologies wherein a model where educational goals and course assessment preferences was used to describe ethnic differences. Selvarajah's (2006) survey instrument incorporates ethnicity of students in its design. This was adopted in the present study as it allows the comparison of Thai students with local and international ANZAC students.

Based on the above literature review the hypotheses presented in this paper are tested with reference to the model shown in Figure 1.

\section{[Insert Figure 1 here]}

\footnotetext{
${ }^{1}$ This paper reported on an exploratory study that looked at the perceptions of Chinese students and New Zealand students of European ancestry to educational goals and assessment methods among 110 postgraduate students in management studies, at the Albany Campus of Massey University in Auckland, New Zealand.
} 
In the current study the effect of Social Motivations and expectations regarding Cooperative Learning are used to model assessment preferences, taking into account demographic data.

\section{METHODOLOGY}

A survey of Postgraduate students was conducted in the Business Faculties of the Auckland University of Technology (AUT) in Auckland, New Zealand, the University Technology Sydney, Australia, the Swinburne University of Technology, Melbourne, Australia and the Shinawatra University, Thailand. The prime data collection method was a self-completion questionnaire, with the same format as the questionnaire previously used by Selvarajah (2006) at the Albany Campus of Massey University in Auckland, New Zealand. The questionnaire was developed by Selvarajah using ideas from Hofstede's (1999) discussion of culture and educational preferences, with some secondary ideas generated from the education-oriented questions in the Executive Survey used in the IMD Report on World Competitiveness (World Economic Forum \& IMD, 1995).

The questionnaire surveyed study motivations using a 5-point Likert scale ( $1=$ 'definitely disagree' to $5=$ 'definitely agree') for 21 statements and educational preferences using the same scale for 37 statements. Finally preferences were compared for four assessment methodologies, namely individual assignments, group assignments, examinations and oral presentations. Students were asked to rank these methodologies from 1 = best to 4 = worst in terms of enjoyment, learning effect, fairness, reliability and overall preference. Unfortunately, only 453 out of the 523 students who returned their questionnaires applied the assessment rating system correctly, a common problem in selfcompleted questionnaires.

In order to test the hypotheses it was necessary to create scales for Cooperative Learning Preference and Social Motivation from the items described above. Exploratory factor analyses were performed separately for the study motivation questions and the educational preference questions, using principal component analysis to extract the initial factors and an oblimin rotation to derive the final factors. The validity and reliability of the resulting scales were checked using confirmatory factor analysis and Cronbach's 
alpha. Goodness of fit criteria (RMSEA $<.08$, CMIN/DF $<3$, GFI $>.90$ ) specified by Byrne (2001) were applied with Cronbach’s alpha above 0.60 (Hair et al, 2005). The first hypothesis was tested using a multivariate general linear model analysis to compare Social Motivation and Cooperative Learning preferences of ANZAC international students with ANZAC and Thai local students.

Assessment preferences for examination, oral presentations and individual/gross assignments were supplied on a 1 to 4 scale in terms of enjoyment, learning value, fairness, as a measure of ability and overall preference. This study focused on a preference for group assignment over individual assignment binary variables were created in order to establish to what extent preferences for group assignments exceeded the preference for individual assignment in the three students groups. Using these binary variables as the dependent variable binary logistic regression was used to test the second hypothesis and compare the preferences for group assignments of international ANZAC students with those of local ANZAC and Thai students while controlling for the effects of social motivation and con-operative learning. Finally, the third hypothesis was tested using structural equation modelling based on Figure 1.

\section{RESULTS}

In the sample of 453 respondents included in this study males (59\%) outnumbered females (41\%). More than half the students (221) were from Australia, with 84 from New Zealand and 148 from Thailand. Of the ANZAC students 42 percent were international students and 25 percent were local students. The majority (54\%) were less than 30 years old, with 19 percent under 25 and only 26 percent aged 35 or above. While 92 percent of the students at the Thai university gave their ethnicity as simply Thai, the ANZAC students were most commonly of Chinese, Indian and European ancestry (see Table 1). The multi-culturalism is therefore confirmed as a more important issue for New Zealand and Australian universities than for Thai universities.

\section{[Insert Table 1 here]}


A single Social Motivational construct emerged from the exploratory factor analysis, producing a valid measurement model $(\mathrm{CMIN} / \mathrm{DF}=2.931$, GFI $=.985$, RMSEA $=.069$ ) and a summated scale with a Cronbach's alpha of .789. A single Cooperative Learning construct for Cooperative Learning also emerged producing a valid measurement model $(\mathrm{CMIN} / \mathrm{DF}=1.201, \mathrm{GFI}=.992, \mathrm{RMSEA}=.022)$ and a summated scale with a Cronbach's alpha of 0.613. This measurement model is shown in Figure 2.

\section{[Insert Figure 2 here]}

The first hypothesis was tested by comparing these scales for ANZAC locals, ANZAC internationals and Thai students while controlling for the effects of gender and age in a multivariate general linear model analysis. A cubic transformation was applied for the Social Motivation scale and a squared transformation for the Cooperative Learning construct, in order to make the model assumptions of normality and homoscedasticity more valid.

Significant differences across these three groups of students were found for both Social Motivation $\left(F(2,374)=70.93, p<.001\right.$, partial $\left.\eta^{2}=.275\right)$ and Cooperative Learning $\left(\mathrm{F}(2,374)=38.34, \mathrm{p}<.001\right.$, partial $\left.\eta^{2}=.170\right)$ with mean values shown in Table 2 . The first hypothesis was not supported in that planned contrasts showed that Thai students showed more Social Motivation than international ANZAC students $(\mathrm{t}(374)=6.76$, $\mathrm{p}<.001)$ and there was no significant difference between international ANZAC students and Thai students in terms of Cooperative Learning $(\mathrm{t}(374)=1.19, \mathrm{P}=.236)$. However, international students did show significantly more Social Motivation $(\mathrm{t}(374)=5.75$, $\mathrm{p}<.001)$ and more Cooperative Learning $(\mathrm{t}(374)=8.30, \mathrm{p}<.001)$ than local ANZAC students.

\section{[Insert Table 2 here]}

In comparison to the above differences the age effect was weak for both Social Motivation $\left(\mathrm{F}(3,374)=3.325, \mathrm{p}=.020\right.$, partial $\left.\eta^{2}=.026\right)$ and Cooperative Learning $\left(F(3,374)=3.352, p=.019\right.$, partial $\left.\eta^{2}=.026\right)$ and the gender effect was not significant in both cases $(\mathrm{F}(1,374)=3.172, \mathrm{p}=.076$ and $\mathrm{F}(1,374)=3.84, \mathrm{p}=.051)$. 
The second column in Table 3 shows that on average students did not think that group assignments were better than individual assignments. In particular only 18 percent of students considered group assignments to provide a better measure of ability than individual assignments, while only 24 percent of students considered group assignments to be more fair than individual assignments and only 30 percent of students considered group assignments to have greater learning value than individual assignments. However, 41 percent of students enjoyed group assignments more than individual assignments and 36 percent of students preferred group assignments to individual assignments. These results confirm the concerns raised by other authors, suggesting that the introduction of group assessment in place of individual assessment is not a popular strategy amongst students and that these concerns need to be addressed by educators. The third, fourth and fifth columns of Table 3 shows a lack of support for the first hypothesis in that Thai students generally seem to show more of a preference for group assignments than ANZAC students. But, as expected, international ANZAC students do show a greater preference for group assignments than local ANZAC students.

\section{[Insert Table 3 here]}

Table 3 also shows the results when binary logistic regression was used to model the probability of a greater preference for group as opposed to individual assignments in terms of Social Motivation, Cooperative Learning and student group. These results show that when we control for Cooperative Learning and Social Motivation there is a significant difference between the group assignment preferences of the three types of student in the case of Overall Preference and Fairness. However, Table 3 also shows that when student type is controlled there is support for the second hypothesis, in that students with higher social motivation tend to have higher regard for group assessment as a measure of ability ( $\mathrm{p}=0.006$ ) while students with a higher preference for cooperative learning tend to have a significantly higher Overall Preference for group assessment.

\section{[Insert Figure 3 here]}

Figure 3 shows the results when the model in Figure 1 was fitted to the data using structural equation modelling. Only significant coefficients are included in this model 
producing an excellent fit (Chi-Square $=7.145$, $\mathrm{df}=6, \mathrm{p}=.308, \mathrm{CMIN} / \mathrm{DF}=1.191, \mathrm{CFI}=$ .997 , RMSEA $=.025)$. This model also provides some support for the second hypothesis in that there is a significant relationship between social motivation and cooperative learning, as well as a significant relationship between social motivation and preference for group assessment as a measure of ability and in terms of fairness. However, when this model is fitted separately for Thai, ANZAC local and ANZAC international students significant differences in the weights are obtained $($ Ch-Square $=128.7, \mathrm{df}=30, \mathrm{p}<.001)$. As shown in Table 4 in the case of both local and International ANZAC students preference for Cooperative Learning is associated with a significant increase in group assessment preference in regard to Enjoyment. However, this is not the case for Thai students. For these students Social Motivation is associated with a significant increase in group assessment preference as an ability measure. Also of interest is the link between Social Motivation and Cooperative Learning. This relationship is not significant for local ANZAC students, however, for ANZAC International and Thai students there is a significant positive relationship.

The above results have shown that there are large differences between Thai students, international ANZAC students and local ANZAC students. Social Motivation is stronger for Thailand. In addition, the relationship between Social Motivation and Cooperative Learning is stronger for these students and so is the preference for group assessment, especially in regard to Fairness (Table 3). It was expected that these relationships would be stronger in the case of international students but it seems that ethnic considerations are more important, suggesting that the third research hypothesis must be rejected. However, this research has shown that international ANZAC students do exhibit a stronger relationship between Social Motivation and Cooperative Learning than local ANZAC students and that, like local ANZAC students, if they enjoy Cooperative Learning they will usually enjoy Group Assignments. When these various preferences measures are combined it appears that Thai and international ANZAC students have more similar levels of overall preference for group assignments while local ANZAC students with similar desires for cooperative learning have a lower preference for Group Assignments (See Table 3). 


\section{SUMMARY AND CONCLUSIONS}

Little support has been found for the research hypotheses. With regard to the first hypothesis, the results show that, contrary to expectation, social motivation is significantly higher for Thai students than for local or international ANZAC students. However, as expected the desire for cooperative learning is strongest for international ANZAC students. Partly because of these differences, the three student groups showed differences concerning preferences for group assessment with Thai students showing the greatest preference for group assessment in all respects except learning value. International ANZAC students showed the greatest appreciation for the learning value of group assessments, probably because of their greater desire for cooperative learning.

With regard to the second hypothesis, a significant positive relationship has been found between social motivation and cooperative learning. However, although a significant direct relationship has been found between social motivation and preference for group assessment as an ability measure and in terms of fairness, it seems that social motivation has no direct relationship with preference for group assessment in terms of learning value, enjoyment or overall preference. This helps to explain the higher preference for group assessment in terms of fairness and as an ability measure observed for the more socially motivated Thai students. Only for Thai students is there a significant direct relationship between social motivation and preference for group assessment as a measure of ability.

In relation to the third hypothesis, there is again little support. The relationship between social motivation and cooperative learning is significant for international ANZAC students but this relationship is actually stronger for Thai students and there are no significant relationship between social motivation and group assessment preferences for international ANZAC students. However, there are significant relationships between cooperative learning and enjoyment of group assessment for both local and international ANZAC students.

In conclusion, it seems that international ANZAC students enjoy cooperative learning more than the other student groups and that they therefore appreciate the learning value of group assessment more than the other student groups. The teaching implications of these results are challenging for universities who wish to promote group 
assessment. The results suggest that, especially for local ANZAC students, individual assessment is preferred to group assessment. The relationship between cooperative learning and enjoyment of group assessment for ANZAC students suggests that the advantages of cooperative learning therefore need to be promoted in Australian and New Zealand universities. More importantly, perceptions of group assessment in terms of fairness and a measure of ability need to be altered in these universities. Only 7\% of local ANZAC students and $18 \%$ of international ANZAC students thought that group assessments were fairer than individual assessments. Only 9\% of local ANZAC students and $18 \%$ of international ANZAC students thought than group assignments produced a better measure of ability than individual assessments.

In the case of Thai universities, high levels of social motivation mean that group assessment is an easier sell. But again, perceptions of group assessment as a measure of ability need attention. Only 26\% of Thai students believe that group assessments provide a better measure of ability than individual assessments. The analysis of the data has therefore identified a number of teaching related implications. We started with the hypotheses that the importance of Social Motivation and preferences for Cooperative Learning would be stronger for international students in Australian and New Zealand students than in Thailand. This was based on the premise that the presence of significant international student populations in Australia and New Zealand would sway the data to display this characteristic when compared to Thailand that lacks this diversity. To the contrary, the evidence shows that Australian and New Zealand students, in particular local ANZAC students, favoured individual assignments. However, it was found that international ANZAC students had the highest appreciation for the Learning Value of group assignments and that, all things considered, they, like Thai students, rated group assignments more favourably than local ANZAC students.

The study indicates that Australia and New Zealand universities, with their high proportions of international students compromising mainly of Asian students (Chinese and Indian), seem to have a wider range of assessment preferences than Thailand where nearly all students surveyed were Thais. Teachers therefore need to address a full spectrum of student assessment preferences and recognise that they may all be present concurrently within the same class of students. This study is useful in this respect because 
it shows that we cannot assume specific assessment style preferences based on ethnicity. Assessment methods must respond to different learning style preferences in addition to conventional assessment instruments such exams and research reports. Assessment methods that engage students, facilitate learning and are more holistic need to be adopted.

Universities in Australia and New Zealand actively seek to recruit increasing numbers of students from Asia, as they have become reliant on them for a significant portion of their non-government funded income. For this reason, student populations will continue to increase in diversity. The most effective teachers will recognise this and adapt their teaching to optimise and enhance student learning and the attainment of academic standards. Educators need to reflect on their assessment practices and accept that there are many realities (both Eastern and Western). In addition, they also need to reflect on how knowledge is constructed and how it can be assessed. In particular they need to acknowledge the advantages of group assessment and look for ways to address the perceived shortcomings of this assessment method.

\section{LIMITATIONS}

Care must be exercised in applying these results to other situations that may have different ethnic make-up. The Australian and New Zealand samples had predominantly Chinese and Indian international students and caution should be exercised in generalising these findings to all international students. Similarly, the Thai sample consisted in the main of ethnic Thais and there is no evidence to show that all homogenous populations will conform to Thai assessment preferences. 


\section{REFERENCES}

Allen R (2004) Foreword, Teaching and Learning in Focus 5 (12):1.

AUT (2005) Auckland University of Technology: Profile 2005-2007, Auckland University of Technology, Auckland.

Barfield RL (2003) Students' perceptions of and satisfaction with group grades and the group experience in the college classroom, Assessment \& Evaluation in Higher Education 28 (4):355-370.

Bejarano Y (1987) A cooperative small-group methodology in the language classroom, TESOL Quarterly 21:483-504.

Bishop R and Glynn T (1999) Culture Counts: Changing Power Relations in Education, Dunmore Press, Palmerston North.

Bloom B, Hastings J and Madaus G (1971) Handbook on Formative and Summative Evaluation of Student Learning, McGraw-Hill, New York.

Brody CM (1995) Collaborative or Cooperative Learning? Complimentary practices for instructional reform, Journal of Staff, Program and Organizational Development 12 (3):133-143.

Byrne BM (2001) Structural Equation Modelling with AMOS: Basic Concepts, Applications and Programming, Lawrence Erlbaum Associates, New Jersey.

Candy PC (1991) Self-direction for Lifelong Learning: A Comprehensive Guide to Theory and Practise, Jossey Bass, San Francisco.

Cavallo, AML and Schaffer, LE (1994) Relationships between students' meaningful learning orientation and their understanding of genetics topics. Journal of Research in Science Teaching, 31:393-418

Clark C (2002) Effective Multicultural Curriculum Transformation Across Disciplines, Multicultural Perspectives 4 (3):37-46.

Cohen E (1994) Designing Group Work, Teachers College Press, New York.

Dornyei Z (1994) Motivation and Motivating in the Foreign Language Classroom, Modern Language Journal 78 (2):73-284.

Dornyei Z (1997) Psychological Processes in Cooperative Learning: Group Dynamics and Motivation, Modern Language Journal 81(1):482-493. 
Garfield J and Gal I (1999) Assessment and Statistics Education: Current Challenges and Direction, International Statistical Review 67:1-12.

Gerlach JM (1994) Is this collaboration?, New Directions for Teaching and Learning 1994 (59):5-14.

Ghaith GM (2002) The Relationship Between Cooperative Learning, Perception of Social Support, and Academic Achievement, System 30:263-273.

Ghaith GM (2003) Effects of the Learning Together Model of Cooperative Learning on English as a Foreign Language Reading Achievement, Academic Self-esteem, and Feelings of School Alienation, Bilingual Research Journal 27 (3):451-474.

Ghaith GM and Yaghi H (1998) Effect of Cooperative Learning on the Acquisition of Second Language Rules and Mechanics, System 26:223-234.

Giroux, HA (1992) Border crossing: Cultural workers and the politics of education, New York: Routledge.

Hair JF, Anderson RE, Tatham RL and Black WC (2005) Multivariate Data Analysis, Prentice-Hall International Inc, New Jersey.

Handy CB (1985) Understanding organizations, Penguin, London.

Hofstede, GH. (2003) Culture's consequences: comparing values, behaviours, institutions and organisations across nations, Sage, Beverly Hills, CA.

Kagan S (1990) The Structural Approach to Cooperative Learning, Educational Leadership 47 (4): 12-15.

Kohn A (1992) No contest: The case against competition, Houghton Mifflin, New York.

Kohn A (1987) It's Hard to Get Left Out of a Pair, Psychology Today October:1- 6.

Lansdale D (1984) Institutional Culture and Third World Student Needs at American University, in Barber EG, Altbach PG and Myers RG (Eds) Bridges to Knowledge, University of Chicago Press, Chicago.

Lauren B (2005) Foreign Students Enrolled Down for First Time in Three Decades, accessed at www.nytimes.com. on 14 January 2005.

Leask B (2001) Bridging the gap: Internationalizing university curricula, Journal of Studies in International Education 5 (2):100-115.

Lee T (2005) Intercultural teaching in higher education, Intercultural Education 16 (3):201-215. 
Lewis R (1997) Assessment of Student Learning, in Morey A and Kitano M (Eds) Multicultural Course Transformation in Higher Education: A Broader Truth, Allyn and Bacon, Boston.

Li M and Campbell J (2008) Asian students' perceptions of group work and group assignments in a New Zealand tertiary institution, Intercultural Education 19 (3):203216.

Long MH and Porter PA (1985) Group Work, Interlanguage Talk, and Second Language Acquisition, TESOL Quarterly 19:207-228.

Lynch E (1997) Instructional strategies, in Morey A and Kitano M (Eds) Multicultural Course Transformation in Higher Education: A Broader Truth, 56-70 Allyn and Bacon, Boston.

Mackinnon D and Manathunga C (2003) Going Global with Assessment: What to do when the Dominant Culture's Literacy Drives Assessment, Higher Education Research \& Development 22 (2):131-144.

Maloof J and White VKB (2005) Team Study Training in College Biology Laboratory, Journal of Biological Education 39 (3):120-124.

McBurnie G (2000) Pursuing Internationalization as a Means to Advance the Academic Mission of the University: An Australian Case Study, Higher Education in Europe XXV (1): 63-73.

McLoughlin C and Luca J (2002) A Learner-centred Approach to Developing Team Skills Through Web-based Learning and Assessment, British Journal of Educational Technology 33 (5):571-582.

Ministry of Education (2004) New Zealand's Tertiary Education Sector Report -Profile \& Trends 2003, accessed at http://www.minedu.govt.nz/index.cfm?layout=document\&documentid=10171 on 13 September 2005.

Morey A (2000) Changing Higher Education Curricula for a Global and Multicultural World, Higher Education in Europe XXV (1): 25-39.

Nordberg D (2008) Group projects: more learning? Less fair? A conundrum in assessing postgraduate business education, Assessment \& Evaluation in Higher Education 33 (5):481-492.

Nieto, S (2000) Affirming diversity: The sociopolitical context of multicultural education (3rd ed.), New York: Longman. 
Olsen RE and Kagan S (1992) About Cooperative Learning, in Kessler C (Ed) Cooperative Language Learning: A Teacher's Resource Book, Prentice Hall, Englewood Cliffs.

Pearson C and Chatterjee S (2004) Expectations and Values of University Students in Transition: Evidence from an Australian Classroom, Journal of Management Education 24 (4):427-446.

Pica T, Young R and Doughty C (1987) The Impact of Interaction on Comprehension, TESOL Quarterly 21 (4):737-758.

Pio E (2004) Karmic Assessment: Evidence from Business Students, Journal of University Teaching and Learning Practice December: 74-89.

Porter JY (2006) Using learning communities to enhance counselling curriculum, accessed at http://counselingoutfitters.com/Porter.htm. on 6 July 2007.

Ross M, Heaney J-G and Cooper M (2007) Institutional and managerial factors affecting international student recruitment management, The International Journal of Educational Management 21 (7):593-605.

Ryan, J and Louie K (2007) False Dichotomy? 'Western' and 'Confucian' concepts of scholarship and learning’ Educational Philosophy and Theory, 39 (4): 432-448.

Ryan RW, Raffel JA and Lovell C (1987) International Students in US Public Administration Programs: Profile, Needs and Program Response, International Journal of Public Administration 10 (1):51-76.

Ryland EK (1992a) International Students in Management: From Silence to Synergy, Journal of Management Education 16: 116-128.

Ryland EK (1992b) International Students at CSU San Bernardino - Obstacles and Opportunities, in Sutter RL (Eds) Internationalising the California State University, CSU Institute for Teaching and Learning, Long Beach.

Selvarajah C (1998) Expatriate Acculturation: A Comparative Study of Recent Chinese Business Migrants in New Zealand, International Journal of Management 15 (1):103112.

Selvarajah C (2006) Cross-cultural Study of Asian and European Student Perception: the Need to Understand the Changing Educational Environment in New Zealand, Journal of Cross Cultural Management 13 ( 2):142-155.

Sen Gupta A (2003) Changing the Focus: A Discussion of the Dynamics of the Intercultural Experience, in Alred G, Byram $M$ and Fleming $M$ (Eds) Intercultural Experience and Education, Multilingual Matters Ltd, Sydney. 
Sherman LW (2000) Postmodern Constructivist Pedagogy for Teaching and Learning Cooperatively on the Web, CyberPsychology and Behavior 3 (1):51-57.

Slavin RE (1980) Cooperative Learning, Review of Educational Research 50:315-342.

Slavin RE (1986) Using Student Team Learning, Johns Hopkins University, Centre for Research on Elementary and Middle Schools, Baltimore.

Slavin RE (1995a) Cooperative Learning: Theory, Research, and Practice Allyn and Bacon, Needham Heights.

Slavin RE (1995b) Research on Cooperative Learning and Achievement: What we Know, what we Nod Know, accessed at www.successforall.net/resource/research/cooplern.htm on 20 September 2005.

Staff T (1995) No Longer Just an Academic Question: Educational Alternatives Come to Taiwan, Chinese - English Bilingual Monthly 20 (3):1-8.

Statistics New Zealand (2001) 2001 Population Census, Statistics New Zealand Office, Auckland.

The Economist (2005) Special report: Higher education. 26 February: 63-65.

Tsai, CC (1998) An analysis of scientific epistemological beliefs and learning orientations of Taiwanese eighth graders, Science Education, 82: 473-489.

Ward C (2001) The Impact of International Students on Domestic Students and Host Institution, accessed at http://www.minedu.govt.nz/index.cfm?layout+document\&documentid=5643 on 13 September 2005.

Ward C (2001) The Impact of International Students on Domestic Students and Host Institutions: a Literature Review, Export Education, Wellington.

Ward C and Masgoret A (2004) The Experiences of International Students in New Zealand:, Ministry of Education, Wellington.

Webb NM (1989) Peer Interaction and Learning in Small Groups, International Journal of Educational Research 13:21-39.

Wong S (2001) Managing Diversity: Institutions and Politics of Educational Change, Rowman \& Littlefield Publishers, New York.

World Economic Forum and IMD (1995) The World Competitiveness Report 1995, 
Figure 1: Model for impacts of social motivation on cooperative learning and assessment

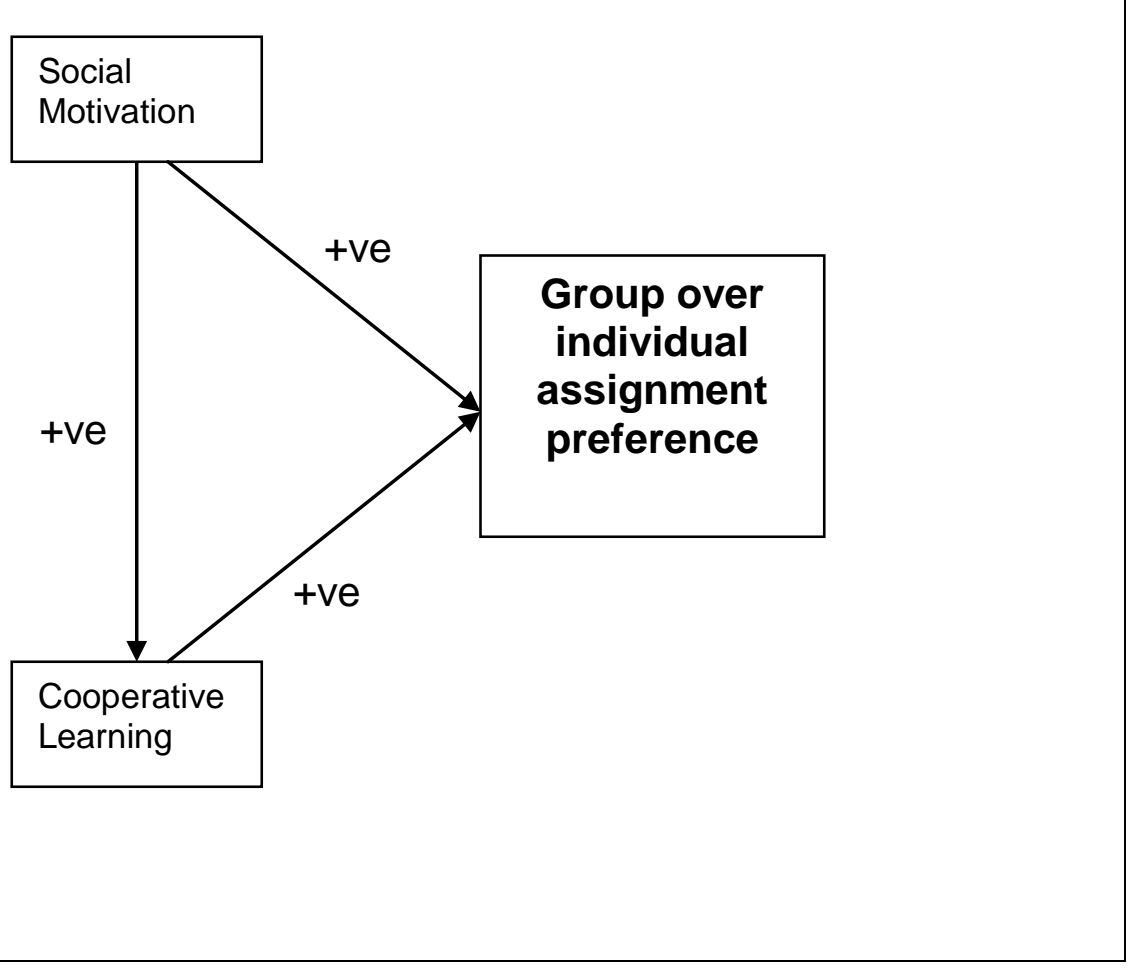


Figure 2: Measurement Model for Social Motivation and Cooperative Learning

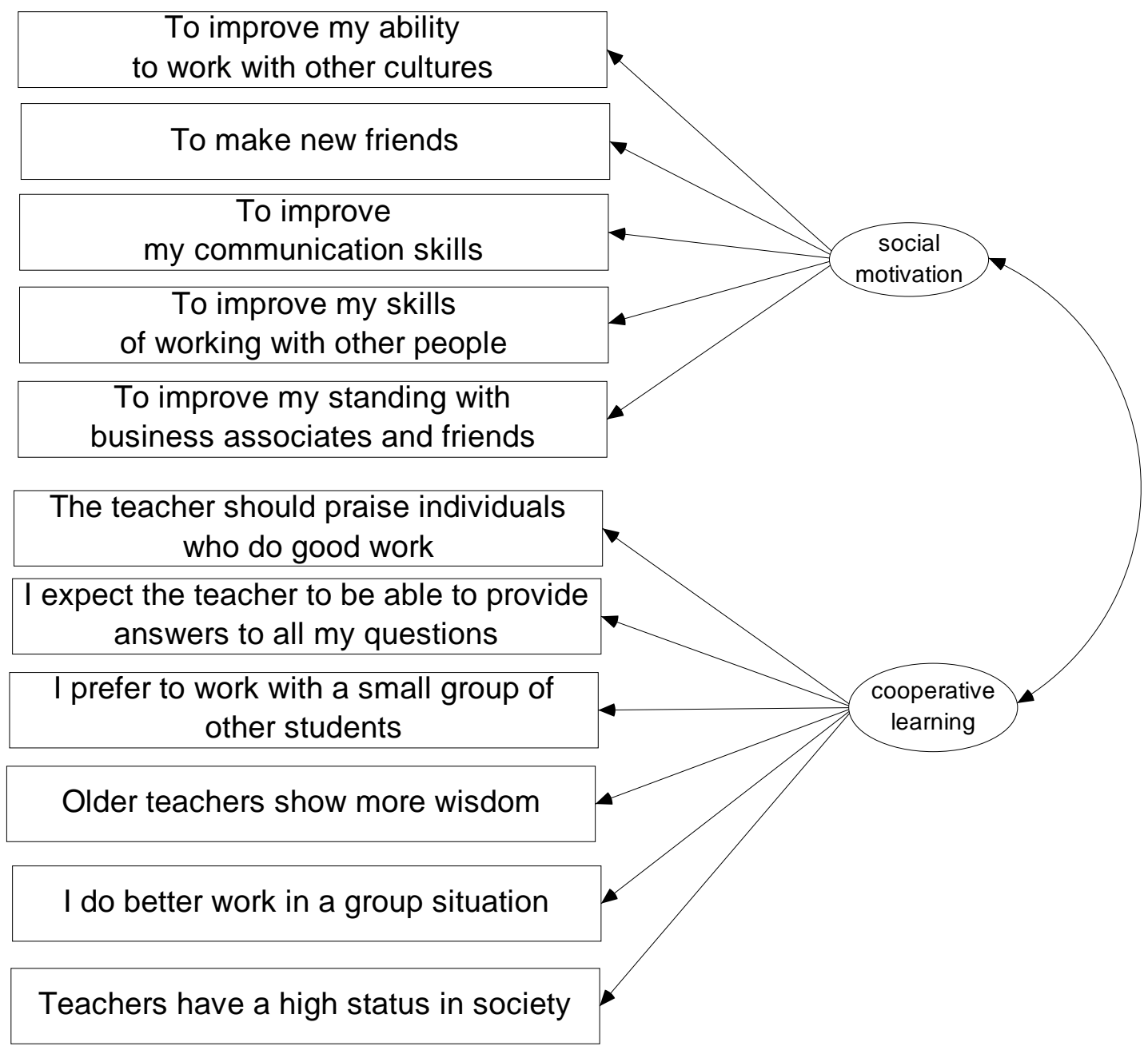


Figure 3: Fitted model for impacts of social motivation on cooperative learning and group assessment preferences

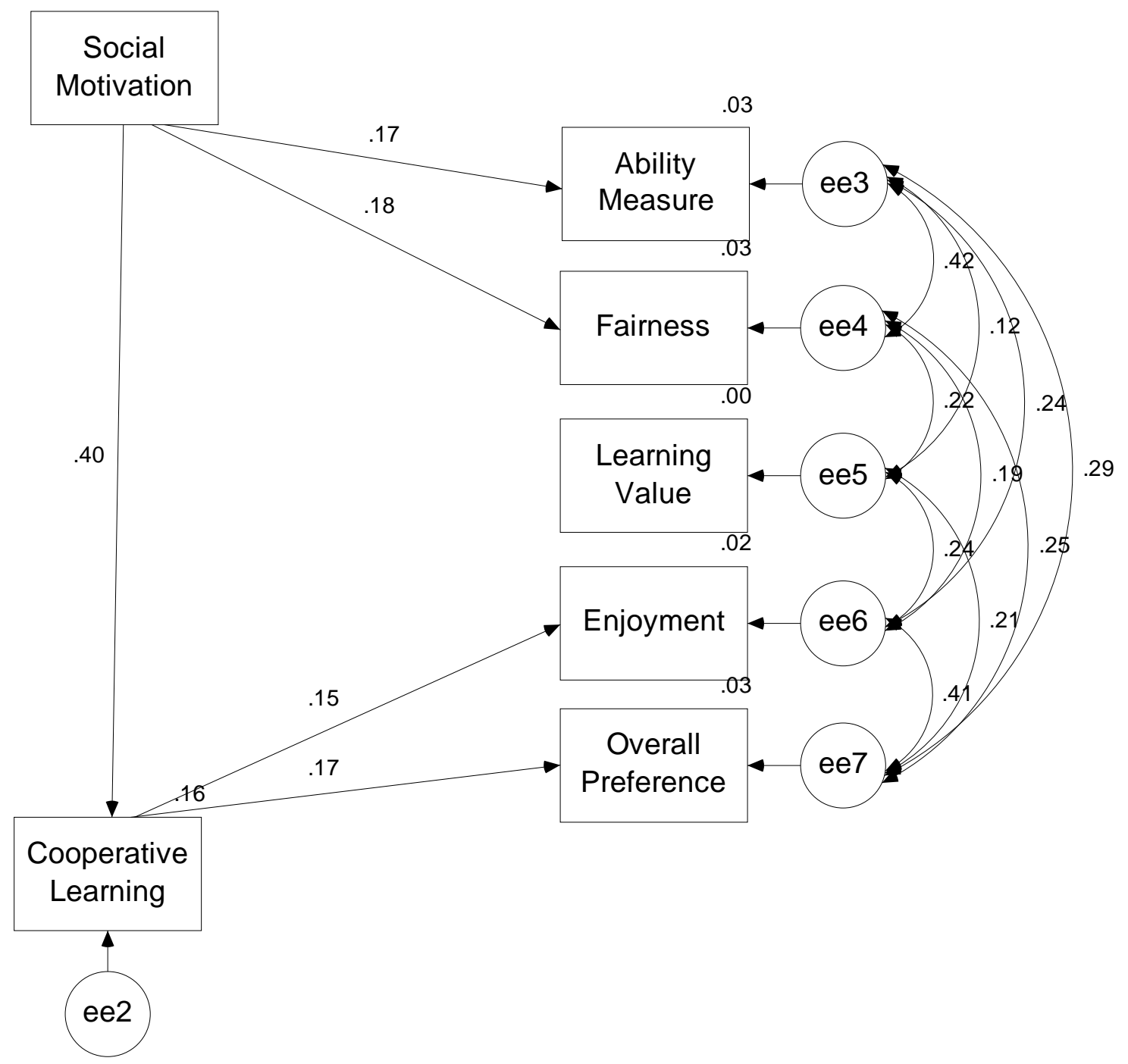


Table 1: Ethnic breakdown for all respondents to the assessment questions

\begin{tabular}{llll}
\hline Ethnicity & ANZAC Local & ANZAC International & Thailand \\
\hline Chinese & $4(4 \%)$ & $83(44 \%)$ & $2(1 \%)$ \\
Indian & $2(2 \%)$ & $38(20 \%)$ & $1(1 \%)$ \\
Thai & 0 & 0 & $92(92 \%)$ \\
European & $65(63 \%)$ & 0 & 0 \\
Other & $34(31 \%)$ & $67(36 \%)$ & $9(6 \%)$ \\
Total & $103(100 \%)$ & $188(100 \%)$ & $148(100 \%)$ \\
\hline
\end{tabular}

Table 2: Comparison of Social Motivation and Cooperative Learning by Student Type

\begin{tabular}{lllllll}
\hline & \multicolumn{2}{l}{$\begin{array}{l}\text { ANZAC } \\
\text { Internationals }\end{array}$} & & & \multicolumn{2}{l}{ ANZAC locals } \\
& Mean & StdDev & Mean & StdDev & Mean & StdDev \\
& 3.89 & .70 & 3.25 & .86 & 4.30 & .44 \\
Social Motivation & 3.60 & .52 & 3.01 & .51 & 3.46 & .59 \\
Cooperative & & & & & & \\
Learning & & & & & & \\
\hline
\end{tabular}


Table 3: Effect of Social Motivation, Cooperative Learning and Student Type (Local/International ANZAC or Thai) on Group Assignment Preference.

\begin{tabular}{|c|c|c|c|c|c|c|c|}
\hline \multirow[b]{2}{*}{ Preference } & \multicolumn{4}{|c|}{$\begin{array}{l}\text { \% Group Assessment Preferred to } \\
\text { Individual Assessment }\end{array}$} & \multicolumn{2}{|c|}{$\begin{array}{l}\text { p-values for Binary } \\
\text { Regression Analysis }\end{array}$} & \multirow{2}{*}{$\begin{array}{l}\text { Logistic } \\
\text { Social }\end{array}$} \\
\hline & All & ANZAC & ANZAC & Thai & Student & Cooperative & \\
\hline & & International & Local & & Type & Learning & Motivation \\
\hline Enjoyment & 40.8 & 42.2 & 32.4 & 45.9 & .309 & .071 & .200 \\
\hline Learning & 30.5 & 34.9 & 26.1 & 28.4 & .485 & .854 & .137 \\
\hline Fairness & 24.1 & 18.3 & 7.2 & 44.6 & $<.001$ & .832 & .187 \\
\hline Ability & 18.3 & 17.7 & 9.0 & 26.4 & .063 & .600 & .006 \\
\hline Overall & 36.0 & 38.5 & 23.4 & 42.6 & .015 & .004 & .558 \\
\hline
\end{tabular}

Table 4: Standardised Weights for Structural Model $\left(* \mathrm{p}<.05,{ }^{* *} \mathrm{p}<.01,{ }^{* * *} \mathrm{p}<.001\right)$

\begin{tabular}{|c|c|c|c|}
\hline Relationship & Thai & $\begin{array}{l}\text { Local } \\
\text { ANZAC }\end{array}$ & $\begin{array}{l}\text { International } \\
\text { ANZAC }\end{array}$ \\
\hline Social Motivation to Cooperative Learning & $.485 * * *$ & .186 & $.320 * * *$ \\
\hline $\begin{array}{l}\text { Cooperative Learning to Overall Preference } \\
\text { for Group Assessment }\end{array}$ & .152 & .162 & .100 \\
\hline $\begin{array}{l}\text { Cooperative Learning to Group Assessment } \\
\text { Preference in the case of Enjoyment }\end{array}$ & .026 & $.221 *$ & $.215 * *$ \\
\hline $\begin{array}{l}\text { Social Motivation o Group Assessment } \\
\text { Preference in the case of an Ability Measure }\end{array}$ & $.389 * * *$ & .105 & -.041 \\
\hline $\begin{array}{l}\text { Social Motivation o Group Assessment } \\
\text { Preference in the case of Fairness }\end{array}$ & .064 & .112 & -.029 \\
\hline
\end{tabular}

